\title{
Optimization of Cutting Parameters to Minimize Tooling Cost in High Speed Turning of SS304 Using Coated Carbide Tool using Genetic Algorithm Method
}

\author{
Muataz Hazza F. Al Hazza, Nur Amirah Najwa Bt Mohmad Bakhari
}

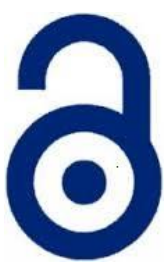

Received: 17 August 2016

Accepted: 30 August 2016

Published: 05 September 2016

Publisher: Deer Hill Publications

(c) 2016 The Author(s)

Creative Commons: CC BY 4.0

\begin{abstract}
High speed turning (HST) is an approach that can be used to increase the material removal rate (MRR) by higher cutting speed. Increasing MRR will lead to shortening time to market. In contrast, increasing the cutting speed will lead to increasing the flank wear rate and then the tooling cost. However, the main factor that will justify the best level of cutting speed is the tooling cost which merges all in one understandable measurable factor for manufacturer. The aim of this paper is to determine experimentally the optimum cutting levels that minimize the tooling cost in machining AISI 304 as a work piece machined by a coated carbide tool using one of the non-conventional methods: Genetic Algorithm (GA). The experiments were designed using Box Behnken Design (BBD) with three input factors: cutting speed, feeding speed and depth of cut and three machining levels.
\end{abstract}

Keywords. High speed turning, tooling cost, AISI 304, MRR

\section{INTRODUCTION}

The development of advanced manufacturing technology has been growing up rapidly. One of the advanced approaches is by increasing the machining speed to increase material removal rate and then shortening time to market, lowering cost, high accuracy and better quality. One approach for reducing the machining time in machining is by increasing the speed turning. High speed turning is difficult to define due to the fact of materials are varied for their hardness. Therefore, high speed turning for one material may still be a low speed for another for example; the high speed for titanium is a low speed for aluminium [1]. However, these technologies should be justified by economic study. One of the most effective tools for economic study is by developing a cost model.

In high speed turning the machining zone will be under high temperature and high sliding velocity. Therefore, the wear progress will be difficult to estimate and predict. However, the wear rate of the cutting tool may give unacceptable outputs and that will result a low quality of surface roughness [2]. However, estimating the tool wear is highly valuable to estimate the tooling cost due to the relationship of tool life and material removal during the life of tool. However, tool insert may reaches its life and should be removed and changed before the tool insert edge cannot give the desired and accepted roughness. If the cutting tool reaches its life very fast then this will lead to increase the tooling cost becomes. Therefore, the manufacturer needs to determine the best cutting levels that minimize the tooling cost. Thus, estimating and then determining the best levels of the independent factors in machining becomes critical and important.

Determining the input level that can give the optimum values in machining process for one output response is very useful if the need for that response is important for one application but needs a validate and reliable mathematical model. In this research a regression empirical model will be developed and then the genetic algorithm method will be used to determine the minimum tooling cost of high speed turning of AISI 304 using coated carbide insert.

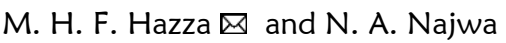

Department of Manufacturing and Materials Engineering

International Islamic University Malaysia

PO Box 10, 50728 Kuala Lumpur, Malaysia

E-mail: muataz@iium.edu.my

Reference: Hazza, M. H. F and Najwa, N. A. (2016). Optimization of Cutting Parameters to Minimize Tooling Cost in High Speed Turning of SS304 Using Coated Carbide Tool using Genetic Algorithm Method. International Journal of Engineering Materials and Manufacture, 1(1), 11-15. 


\section{METHODOLOCY}

The methodology was three related integrated parts: firstly, the experimental work based on the theoretical study, then developing the cost model based on the experimental work. Finally, using the genetic algorithm in order to determine the best cutting levels that will give the minimum tooling cost. Box Behnken design (BBD) has been used in this research to conduct the experimental work for three independent factors: cutting speed, feeding speed and depth of cut. Three levels: $-1,0$, and 1 . However, BBD is easy to conduct in addition to the ability of sequentially. Figure 1 concluded the activities and tasks need to be done in order to achieve the objective of the research in developing tooling cost and then determine the optimum cutting parameters to minimize the tooling cost in high speed turning for SS304 Using Coated Carbide Tool.

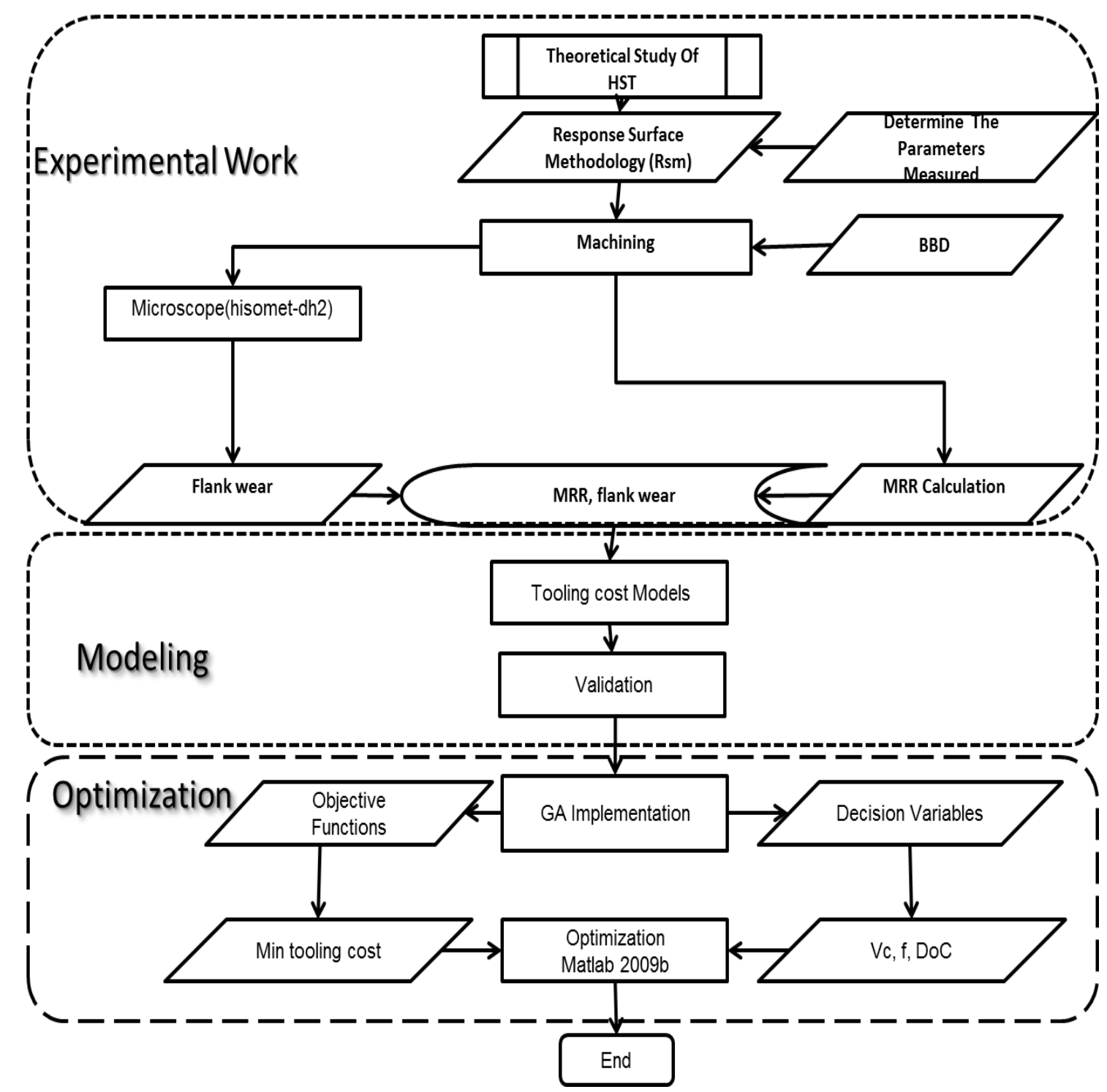

Figure 1: Research methodology.

\section{EXPERIMENT PROCEDURE}

Experimental works was conducted on CNC turning machine type Power Path $15 \mathrm{HS}$ - High Speed Version (spindle ASA A 2-5") and the insert chosen for this study was a coated cemented carbide type (TNGA 160408 T1020) to turn work piece of AISI 304. Under dry cutting conditions with cutting speed from 500 up to $700 \mathrm{~m} / \mathrm{min}$, feed speed of 1000 to $2000 \mathrm{~mm} / \mathrm{min}$ and depth of cut 0.1 to $0.3 \mathrm{~mm}$. Based on BBD with three centre points, fifteen run have been conducted. Table 1 shows the machining levels. 
Table 1: Machining levels.

\begin{tabular}{|l|l|l|}
\hline & Max & Min \\
\hline Cutting speed $(\mathrm{m} / \mathrm{min})$ & 500 & 700 \\
\hline Feeding speed $(\mathrm{mm} / \mathrm{min})$ & 1000 & 2000 \\
\hline Depth of cut $(\mathrm{mm})$ & 0.1 & 0.3 \\
\hline
\end{tabular}

\section{DEVELOPMENT OF TOOLING COST MODEL}

Tooling cost model developed based and is limited in this research to the cost of tool holder and tool insert. The model was developed based on calculating the cost of removal one cubic centimetre. Actually, tooling cost is inversely proportional with tool life and proportional with the machining time Therefore, the tooling cost is calculated based on the work of [4-7]. The machining time components used in this research was based on machining time model developed by [6]. However, the final tooling cost was calculated based on the following equation [3]: However, all the experimental results is concluded in Table 2. The results was analysed using the DoE 6.0.8. The analysis of variance (ANOVA) was conducted to develop an empirical model that can be used to estimate the tooling cost. Analysis of variance (ANOVA) is concluded in Table 3 which shows significant with value of 0.002 and lacks of fit of 0.9574 . Therefore, the model can be used to navigate the design space. The following model has been used to determine the optimum cutting levels in the boundary of the design that can minimize the tooling cost.

\section{GENETIC ALGORITHM}

The genetic algorithm has been implemented using the developed model in the previous section in order to minimize the total tooling cost using three different independent decision variables: cutting speed, feed speed and depth of cut. Table 4 concluded the objective functions decision variables, constrains. In the implementation, the chromosome values of each individual are generated randomly from the ranges of these values. However, the simulation has been repeated for four different runs, each for 1000 iterations. The optimum results was concluded in Table 5. Finally Figure 2 shows the results for different runs that give the minimum tooling cost. The results show for different runs that after 100 iterations the values of the objective function become stable and only few points are giving results far from the final one.

$$
\operatorname{Cost}\left(R m / \mathrm{Cm}^{3}\right)=\frac{C_{T c}(R m)}{M R V\left(\mathrm{~cm}^{3}\right)}
$$

Table 2: Result of experiment.

\begin{tabular}{|c|c|c|c|c|}
\hline No. of Run & $\begin{array}{c}\text { Cutting Speed }[\mathrm{Vc}] \\
(\mathrm{m} / \mathrm{min})\end{array}$ & $\begin{array}{c}\text { Feeding Speed } \\
{[\mathrm{Vf}](\mathrm{mm} / \mathrm{min})}\end{array}$ & $\begin{array}{c}\text { Depth of Cut } \\
{[\mathrm{d}](\mathrm{mm})}\end{array}$ & $\begin{array}{c}\text { Tooling Cost } \\
\left(\mathrm{RM} / \mathrm{cm}^{3}\right)\end{array}$ \\
\hline 1 & 700.00 & 1500.00 & 0.30 & 0.051136 \\
\hline 2 & 700.00 & 1500.00 & 0.10 & 0.273389 \\
\hline 3 & 500.00 & 2000.00 & 0.20 & 0.157189 \\
\hline 4 & 600.00 & 1500.00 & 0.20 & 0.053346 \\
\hline 5 & 500.00 & 1500.00 & 0.10 & 0.193171 \\
\hline 6 & 700.00 & 2000.00 & 0.20 & 0.267183 \\
\hline 7 & 600.00 & 2000.00 & 0.10 & 0.100728 \\
\hline 9 & 600.00 & 1000.00 & 0.10 & 0.096816 \\
\hline 10 & 600.00 & 1500.00 & 0.20 & 0.177876 \\
\hline 11 & 600.00 & 1500.00 & 0.20 & 0.592315 \\
\hline 12 & 600.00 & 2000.00 & 0.30 & 0.078657 \\
\hline 13 & 600.00 & 1000.00 & 0.30 & 0.588838 \\
\hline 14 & 700.00 & 1000.00 & 0.20 & 0.176317 \\
\hline 15 & 500.00 & 1000.00 & 0.20 & 0.160914 \\
\hline 17 & 500.00 & 1500.00 & 0.30 & 0.173868 \\
\hline
\end{tabular}


Table 3: ANOVA table for tooling cost.

\begin{tabular}{|c|c|c|c|c|c|c|}
\hline Source & $\begin{array}{l}\text { Sum of } \\
\text { Squares }\end{array}$ & DF & $\begin{array}{l}\text { Mean } \\
\text { Square }\end{array}$ & $\begin{array}{c}\mathrm{F} \\
\text { Value }\end{array}$ & Prob $>F$ & \\
\hline Model & 0.30711 & 9 & 0.034123 & 20.18702 & 0.0020 & significant \\
\hline A & 0.060565 & 1 & 0.060565 & 35.82974 & 0.0019 & \\
\hline$B$ & 0.038284 & 1 & 0.038284 & 22.64872 & 0.0051 & \\
\hline$C$ & 0.088878 & 1 & 0.088878 & 52.57925 & 0.0008 & \\
\hline $\mathrm{A} 2$ & 0.016824 & 1 & 0.016824 & 9.952853 & 0.0252 & \\
\hline B2 & 0.062186 & 1 & 0.062186 & 36.78888 & 0.0018 & \\
\hline $\mathrm{C} 2$ & 0.008493 & 1 & 0.008493 & 5.024655 & 0.0751 & \\
\hline$A B$ & 0.033702 & 1 & 0.033702 & 19.93782 & 0.0066 & \\
\hline $\mathrm{AC}$ & 0.138012 & 1 & 0.138012 & 81.64661 & 0.0003 & \\
\hline$B C$ & 0.04324 & 1 & 0.04324 & 25.58052 & 0.0039 & \\
\hline Residual & 0.008452 & 5 & 0.00169 & & & \\
\hline Lack of Fit & $6.82 \mathrm{E}-06$ & 1 & $6.82 \mathrm{E}-06$ & 0.003231 & 0.9574 & not significan \\
\hline Pure Error & 0.008445 & 4 & 0.002111 & & & \\
\hline Cor Total & 0.315562 & 14 & & & & \\
\hline
\end{tabular}

Tooling cost $=+1.47020-9.44817 \mathrm{E}-003 *$ Cutting speed+4.16756E-003 * feed speed-9.82922* depth of cut+7.34688E-006* Cutting speed2-6.96458E-007 * feed speed2 +5.22014* depth of cut22.80425E-006* Cutting speed * feed speed+0.018575* Cutting speed * depth of cut-3.17638E$003 *$ feed speed * depth of cut

Table 4: GA objectives, decision variables, constrains and parameters.

\begin{tabular}{|c|c|c|l|}
\hline Objective function & Decision variables & constrains & \\
\hline Minimize Tooling cost & Cutting speed & $500 \geq V c \geq 700$ & Number of Individuals in Population= 20 \\
& Feeding speed & $1000 \geq V c \geq 2000$ & Number of generation= 1000 \\
& Depth of cut & $0.1 \geq V c \geq 0.3$ & Crossover Rate $=35 \%$ \\
& & & Mutation Rate $=8 \%$ \\
\hline
\end{tabular}

Table 5: GA optimization results.

\begin{tabular}{|c|c|c|c|c|}
\hline Run & Cutting speed & Feeding speed & Depth of cut & Tooling cost \\
\hline 1 & 500 & 2000 & 0.3 & 0.35779 \\
\hline 2 & 500 & 1989 & 0.3 & 0.035988 \\
\hline 3 & 500 & 1467 & 0.3 & 0.046178 \\
\hline 4 & 500 & 1276 & 0.3 & 0.049914 \\
\hline
\end{tabular}



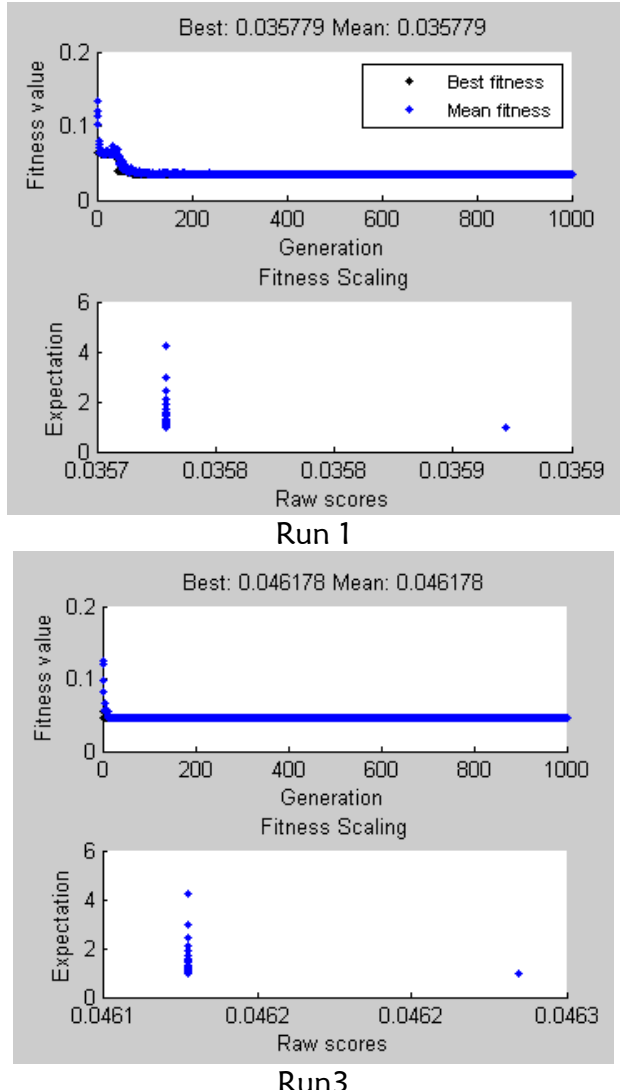

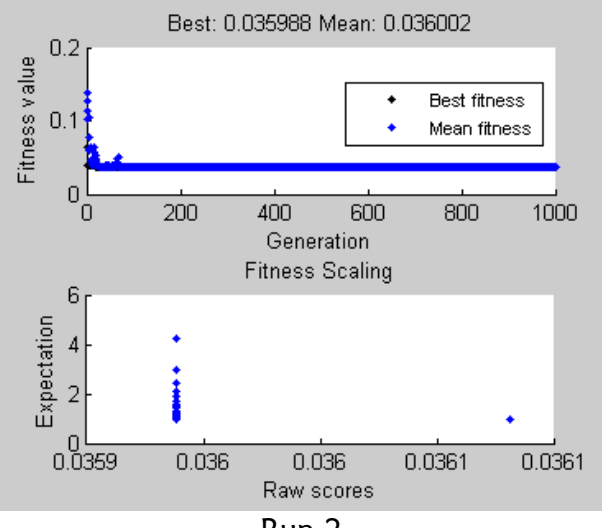

Run 2

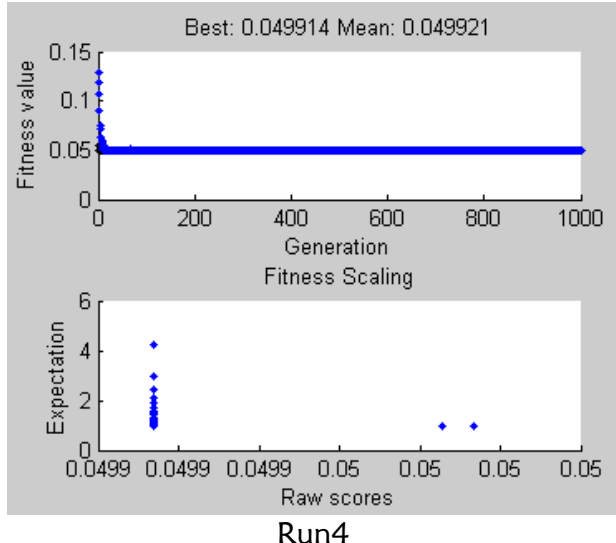

Run4

Figure 2: four different runs for 1000 iteration.

\section{CONCLUSIONS}

Results concluded in table 5, show that the main flexible factor is the feeding speed which varied from 1276 to 2000 $\mathrm{mm} / \mathrm{min}$. In contrast, the cutting speed and depth of cut is constant with the values of $500 \mathrm{~m} / \mathrm{min}$ and $0.3 \mathrm{~mm}$. The results show that to minimize tooling cost, the cutting speed should be in the lowest level while the depth of cut should be in the maximum level. In addition the lowest tooling speed will be achieved in the highest feeding speed.

\section{REFERENCES}

1. Muataz Hazza F. Al Hazza, H., Nabilah, M. Yusof, B. M., Najwa, N. A., Eikhwan, M., Khazairul, M., \& Taha, A. H. (2013). Experimental Study of flank wear in High Speed Turning of Stainless Steel AISI 304. Journal of Advanced Science and Engineering Research, 3(2), 96-103.

2. Ozel, T. and Nadgir, A. (2002). Predictions of flank wear by using back propagation neural network modeling when cutting hardened $\mathrm{H}-13$ steel with chamfered and honed $\mathrm{CBN}$ tools. International Journal of Machine Tools \& Manufacture, 42(2), 287-297.

3. Adesta, E. Y. T., Al Hazza, M., Agusman, D., \& Sutjipto, A. G. E. (2012). Development of Tooling Cost Model for High Speed Hard Turning. Advanced Materials Research, 418, 1482-1485.

4. Gara, S., Bouzid, W., Hbaieb, M., \& Amar, M. B. (2007). Cutting speed optimization in high speed turning. International Review in Mechanical Engineering, 1, 237-244.

5. Gara, S., Bouzid, W., Ben Amar, M. and Hbaieb M. (2008). Cost and time calculation in rough NC turning. International Journal Advanced Manufacturing Technology, 40(9-10), 971-981.

6. Adesta, E. Y. T., \& Al Hazza, M. H. (2011). Machining Time Simulation in High Speed Hard Turning. Advanced Materials Research, 264, 1102-1106.

7. Al Hazza, M. H. F., Konneh, M., Iqbal, M., Taha, A. H., \& Hasan, M. H. (2015). Using the Desirability Function as an Effective Tool in Target Costing Model. Advanced Materials Research, 1115, 126-129).

8. Kalpakjian Serope and Steven R. Schmid, 2010. Manufacturing engineering technology. Machining centers, machine tool structures and machining economics (pp 208). Prentice Hall. 